\title{
Impact of ablation duration on rhythm outcome after concomitant maze procedure using cryoablation in patients with persistent atrial fibrillation
}

Dong Seop Jeong ${ }^{\dagger}$, Ji Hoon You, Chang-Seok Jeon ${ }^{\dagger}$, Pyo Won Park ${ }^{*}$, Kiick Sung, Wook Sung Kim and Young Tak Lee

\begin{abstract}
Background: The aim of this study was to evaluate the impact of ablation duration during a maze procedure using a nitrous oxide-based cryosurgical system.

Methods: From May 2001 to December 2006, 256 consecutive patients who underwent a concomitant maze procedure using nitrous oxide-based cryoablation for chronic atrial fibrillation (AF) during cardiac surgery were enrolled. The ablation duration for each lesion was between $120 \mathrm{~s}$ at $-60^{\circ} \mathrm{C}$ in 140 patients (control group) and $160 \mathrm{~s}$ in 116 patients (long duration group).

Results: One in-hospital death occurred, and a permanent pacemaker was implanted in one patient (0.4\%). At discharge, absence of AF was noted in $84.5 \%$ of the long duration group and in $87.1 \%$ of the control group. During follow up, patients in the long duration group achieved and maintained the absence of AF at a higher rate than the control patients ( $96 \%$ vs. $84 \%$ at 24 months, respectively: $P=0.008$ ). Multivariable analysis identified long AF duration as the only independent predictor of AF recurrence. At late follow up, left atrial mechanical activity was less frequent in the control group than in the long duration group. The mean left atrial volume index was lower in the long duration group than in the control group.
\end{abstract}

Conclusion: The modified cryomaze procedure is safe and effective. Ablation time plays an important role in achieving and maintaining the absence of AF. Long cryoablation duration is recommended for optimal cryomaze results.

Keywords: Atrial fibrillation, Ablation, Maze operation, Left atrial activity

\section{Background}

Atrial fibrillation (AF) is the most common arrhythmia and is also a common condition in patients with heart disease. The maze procedure is a useful modality for sinus rhythm restoration in patients with AF undergoing cardiac valve surgery. The "cut-and-sew" Cox maze procedure was introduced in 1987 and is considered the gold standard for the surgical treatment of AF [1-3]. Although the conventional maze procedure produced

\footnotetext{
* Correspondence: pwpark@skku.edu

${ }^{\dagger}$ Equal contributors

Department of Thoracic and Cardiovascular Surgery, Cardiac and Vascular

Center, Samsung Medical Center, Sungkyunkwan University School of

Medicine, 81 Irwon-ro, Gangnam-gu, Seoul 06351, South Korea
}

excellent results, it has not gained widespread use because of its complexity. For this reason, many surgeons have modified the maze procedure with various energy sources such as radiofrequency, cryoablation, microwave, ultrasound, and laser energy. In particular, the cryomaze procedure has an excellent clinical safety record $[4,5]$. However, the most appropriate ablation duration for achieving long-term isolation has not been definitely established. The purpose of this study was to evaluate the effect of ablation duration on cryomaze rhythm outcomes. 


\section{Methods}

\section{Study population}

A total of 256 consecutive patients were enrolled between May 2001 and December 2006 for this study. All patients underwent the cryoablation maze procedure concomitant with cardiac surgery for persistent or long-standing AF. Patients with paroxysmal AF were excluded. Additional exclusion criteria for the cryomaze procedure included: a very large left atrium (LA) over $80 \mathrm{~mm}$, atrial calcification, and significant tricuspid regurgitation associated with severe right atrial enlargement. Patients with successful rhythm control were defined as those who recovered normal sinus rhythm within a window period of 3 months after the maze operation and showed no evidence of AF recurrence thereafter, irrespective of anti-arrhythmic agent use during the follow-up period. The Institutional Review Board of Sungkyunkwan University School of Medicine approved this study, and the requirement for patient consent was waived.

\section{Operative procedures}

The modified Cox maze procedure using cryoablation was performed according to published principles and procedures [6]. Briefly, cryoablation lesions were created endocardially with custom-made straight $(6 \mathrm{~cm})$ and Tshaped $(4 \mathrm{~cm})$ probes (Frigitronics, Cooper Surgical). Cryogenerators were set at $-60{ }^{\circ} \mathrm{C}$ in both groups and the ablation duration was determined according to the surgeon's discretion. The LA box and connecting lesions into the posterior mitral annulus were made. The reduction of LA dimensions by partial resection of the atrial wall has been performed since 2005. The left atrial reduction was performed as often as possible, i.e. whenever the LA was greater than $60 \mathrm{~mm}$ on preoperative echocardiography. The LA appendage was obliterated internally using a running suture with 4-0 prolene. Other techniques such as external ligation, external stapled exclusion, stapled excision, or combinations of techniques were not performed. A right atrial isthmus lesion and a lesion from the superior vena cava to the inferior vena cava were created (Fig. 1). We occasionally added a lesion from the right atrial appendage to the tricuspid valve annulus in cases with a dilated right atrium. Modified ultrafiltration was used routinely.

\section{Postoperative management and follow-up}

Oral amiodarone (200 mg/day) was administered postoperatively for 2 to 3 months and then withdrawn if there was no AF recurrence. If patients exhibited AF during their hospital stay, 20 to $40 \mathrm{mg} / \mathrm{h}$ of amiodarone was given intravenously without loading, followed by oral amiodarone at $200 \mathrm{mg}$ twice a day and then $200 \mathrm{mg} /$ day. Electrical cardioversion was used only in patients with atrial flutter-fibrillation. After 3 to 6 months, oral anticoagulation was withdrawn in the absence of thrombogenic risk factors such as stroke history and mechanical valve replacement. Standard 12-lead electrocardiography was assessed at 1, 3, 6, 9, and 12 months postoperatively and every 6 months thereafter. If patients complained of symptoms suggestive of AF recurrence at any time, electrocardiography and 24-h Holter monitoring were repeated.

Transthoracic echocardiography was performed prior to surgery, before discharge, and during follow-up (3 to 6 months and then $1,3,5$, and $>7$ years postsurgery). Left ventricular (LV) end-systolic and diastolic dimensions were obtained from the parasternal view based on the American Society of Echocardiography guidelines [7]. The LV ejection fraction was calculated using Simpson's method from the parasternal view. The LA dimensions were measured in M-mode tracing from a parasternal long-axis view. The LA volumes were assessed using the ellipsoid (length-diameter) method and corrected to body surface area (LA volume index,
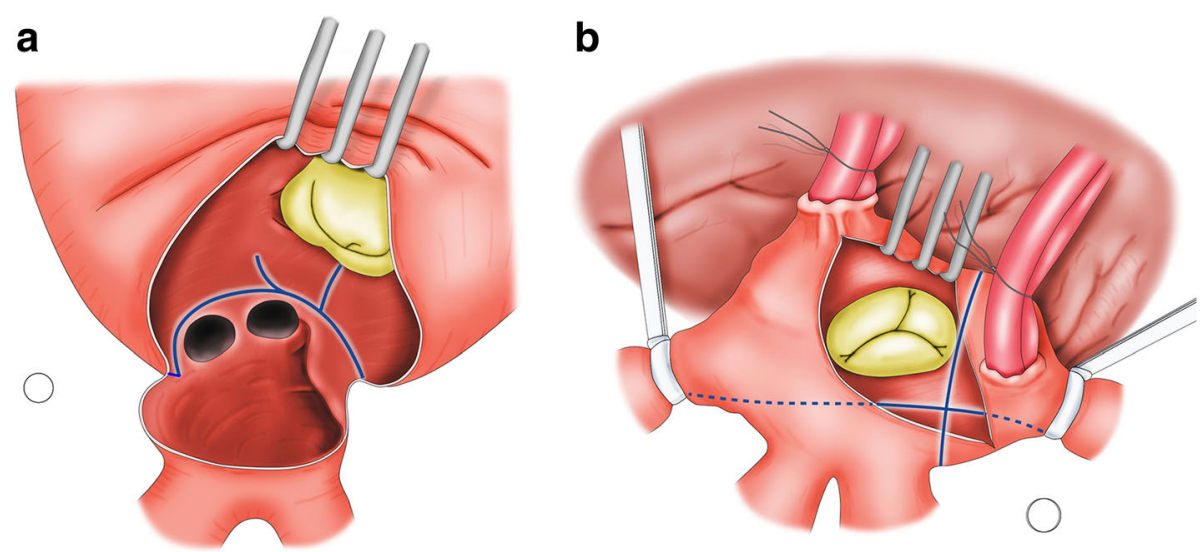

Fig. 1 Operative scheme of the modified maze procedure using cryoablation. Left atrial procedure (Blue line: cryoablation) (a) and Right atrial procedure (Blue line: cryoablation) (b) 
LAVI). The transmitral peak velocities of the early and late filling waves were measured in the apical 4-chamber view. The absence of a late filling wave on the tracings was considered to indicate the absence of mechanical atrial contraction.

\section{Statistical analysis}

All statistical analyses were performed using PASW Statistics 19 software (SPSS Inc., Chicago, IL, USA). For comparisons between the two groups, the $\chi^{2}$ test or Fisher's exact test was used for categorical variables, and the unpaired Student's $t$ test was used for continuous variables. Cox proportional hazards regression analysis was performed to identify predictors of outcomes. Covariates that were entered into the model included age, sex, NYHA functional class, diabetes status, hypertension, duration of AF, prior stroke, renal function, serum parameters, and preoperative echocardiographic data. If the $P$ value of a covariate was $<0.20$ in univariate analysis, it was entered into a multivariate analysis model. $P$ values $<0.05$ were considered significant.

\section{Results}

\section{Patient characteristics}

The preoperative patient characteristics are shown in Table 1. Cryoablation was applied for $120 \mathrm{~s}$ in $140 \mathrm{pa}-$ tients (control group) and for $160 \mathrm{~s}$ in 116 patients (long duration group). No intergroup differences were found, except for the incidence of diabetes. The patient operative data are listed in Table 2. Mitral valve procedures were performed in $91.8 \%$ of all patients $(235 / 259)$. No

Table 1 Patient baseline characteristics

\begin{tabular}{|c|c|c|c|}
\hline & $\begin{array}{l}\text { Control } \\
(n=140)\end{array}$ & $\begin{array}{l}\text { Long duration } \\
(n=116)\end{array}$ & $P$-value \\
\hline Age, y & $54 \pm 12$ & $55 \pm 13$ & 0.356 \\
\hline Female sex, n (\%) & $78(56 \%)$ & $74(64 \%)$ & 0.190 \\
\hline Mean AF duration, months & $47 \pm 58$ & $37 \pm 43$ & 0.242 \\
\hline AF duration $\geq 10$ years, $\mathrm{n}(\%)$ & $16(11 \%)$ & $11(10 \%)$ & 0.614 \\
\hline NYHA class III-V, n (\%) & $88(63 \%)$ & $68(59 \%)$ & 0.335 \\
\hline History of stroke, n (\%) & $20(14 \%)$ & $23(20 \%)$ & 0.238 \\
\hline Diabetes, n (\%) & $9(6 \%)$ & $16(14 \%)$ & 0.048 \\
\hline Coronary artery disease, n (\%) & $8(6 \%)$ & $12(10 \%)$ & 0.169 \\
\hline Hypertension, n (\%) & $29(21 \%)$ & $26(22 \%)$ & 0.742 \\
\hline Redo operation, n (\%) & $8(6 \%)$ & $2(2 \%)$ & 0.118 \\
\hline \multicolumn{4}{|l|}{ Echocardiographic data } \\
\hline Left atrial diameter, mm & $56 \pm 8$ & $58 \pm 9$ & 0.090 \\
\hline LVEF, \% & $56 \pm 9$ & $59 \pm 9$ & 0.051 \\
\hline TR grade, moderate to severe & $17(12 \%)$ & $13(11 \%)$ & 0.971 \\
\hline
\end{tabular}

NYHA New York Heart Association functional class, AF atrial fibrillation, LVEF left ventricular ejection fraction, $T R$ tricuspid regurgitation
Table 2 Patient operative data

\begin{tabular}{|c|c|c|c|}
\hline & $\begin{array}{l}\text { Control } \\
(n=140)\end{array}$ & $\begin{array}{l}\text { Long duration } \\
(n=116)\end{array}$ & $P$-value \\
\hline \multicolumn{4}{|l|}{ Mitral valve procedure } \\
\hline MVR & $78(56 \%)$ & $65(56 \%)$ & 0.959 \\
\hline MVP & 55 (39\%) & $37(32 \%)$ & 0.220 \\
\hline Aortic valve procedure & $46(33 \%)$ & $34(29 \%)$ & 0.542 \\
\hline Tricuspid valve procedure & $122(87 \%)$ & $94(81 \%)$ & 0.180 \\
\hline ASD closure & $10(7 \%)$ & $6(5 \%)$ & 0.517 \\
\hline CABG & $1(1 \%)$ & $6(5 \%)$ & 0.049 \\
\hline \multicolumn{4}{|l|}{ Single valve procedure } \\
\hline MVP & 3 & 7 & \\
\hline MVR & 2 & 3 & \\
\hline AVR & 3 & 7 & \\
\hline TVR / TVP & 2 & 3 & \\
\hline \multicolumn{4}{|l|}{ Double valve procedures } \\
\hline $\mathrm{MVP}+\mathrm{TVP} / \mathrm{TVR}$ & 34 & 25 & \\
\hline $\mathrm{MVP}+\mathrm{AVP} / \mathrm{AVR}$ & 3 & 0 & \\
\hline$M V R+T V R / T V P$ & 51 & 40 & \\
\hline $\mathrm{MVR}+\mathrm{AVR} / \mathrm{AV} P$ & 6 & 2 & \\
\hline$A V R / A V P+T V P / T V R$ & 1 & 0 & \\
\hline \multicolumn{4}{|l|}{ Triple valve procedures } \\
\hline $\mathrm{MVP}+\mathrm{TVP}+\mathrm{AVP}$ & 7 & 4 & \\
\hline $\mathrm{MVR}+\mathrm{AVR}+\mathrm{TVR} / \mathrm{TV} P$ & 19 & 20 & \\
\hline$A V R+T V P+M V P$ & 8 & 1 & \\
\hline Left atrial reduction & $36(25 \%)$ & $42(36 \%)$ & 0.077 \\
\hline Miscellaneous & 1 & 4 & \\
\hline CPB time (min) & $152 \pm 48$ & $143 \pm 45$ & 0.129 \\
\hline ACC time (min) & $131 \pm 91$ & $115 \pm 36$ & 0.076 \\
\hline
\end{tabular}

$M V R$ mitral valve replacement, MVP mitral valve plasty, $A S D$ atrial septal defect, $C A B G$ coronary artery bypass grafting, AVR aortic valve replacement, AVP aortic valve plasty, TVR tricuspid valve replacement, TVP tricuspid valve plasty, $C P B$ cardiopulmonary bypass, ACC aortic cross-clamp, LA left atrium

intergroup differences were observed with respect to cardiopulmonary bypass time or aortic cross clamp time.

\section{Postoperative outcomes}

One in-hospital death occurred (0.4\%). The patient, who required preoperative extracorporeal membrane oxygenator support, died after left ventricular volume reduction surgery for dilated cardiomyopathy that developed after atrial septal defect closure. Five patients underwent cardioversions to restore sinus rhythm against typical atrial flutter $(n=3)$ and early recurrence of atrial fibrillation $(n=2)$. Permanent pacemaker implantation was required in one patient due to sick sinus syndrome. The early postoperative data are summarized in Table 3. There was no significant difference in intensive care unit days or hospital stay between the two groups. Postoperative complications 
Table 3 Patient postoperative results

\begin{tabular}{llll}
\hline & $\begin{array}{l}\text { Control } \\
(n=140)\end{array}$ & $\begin{array}{l}\text { Long duration } \\
(n=116)\end{array}$ & $P$-value \\
\hline ICU stay (days) & $1.9 \pm 2.5$ & $2.0 \pm 1.9$ & 0.580 \\
Hospital stay (days) & $12 \pm 7$ & $12 \pm 10$ & 0.743 \\
In-hospital mortality, n (\%) & $1(1)$ & 0 & 0.547 \\
Complications, n (\%) & & & \\
$\quad$ Postoperative bleeding & $5(4)$ & 0 & 0.066 \\
Wound infection & $2(2)$ & $4(3)$ & 0.415 \\
Pacemaker implantation & 0 & $1(1)$ & 0.453 \\
Acute kidney injury & $3(2)$ & $1(1)$ & \\
IABP or ECMO & $1(1)$ & $1(1)$ & 0.999 \\
CVA & 0 & 0 & 0.999 \\
Cardioversion & $1(1)$ & $4(3)$ & 0.179 \\
\hline
\end{tabular}

ICU intensive care unit, IABP intra-aortic balloon pump, ECMO extracorporeal cardiopulmonary support, CVA cerebrovascular accident

included low cardiac output syndrome requiring extracorporeal membrane oxygenator in 2 patients $(0.8 \%)$. Reexploration for bleeding and wound infection occurred in five $(1.9 \%)$ and six patients (2.3\%), respectively.

The overall rate of cardiac-related mortality was $0.2 \%(4 / 255)$; no intergroup difference was observed [2\% (3/139) in the control group versus $1 \%(1 / 116)$ in the long duration group; $P=0.629]$.

\section{Rhythm outcomes}

At the time of hospital discharge, sinus rhythm was observed in $87.1 \%$ of the control group and $84.5 \%$ of the long duration group. Over time, the incidence of sinus rhythm restoration increased in both groups (Fig. 2). However, the rate of freedom from AF recurrence was higher in the long duration group than in the control group at 18 months and at 24 months postsurgery (Fig. 2a). The rate of freedom from off-drug AF recurrence was also higher in the long duration group than in the control group at 24 months postoperation (Fig. 2 b).

In the control group, univariate analysis revealed that long AF duration, hypertension, and enlarged left atrium were associated with late AF recurrence. Multivariable analysis identified long AF duration and enlarged left atrium as independent predictors of AF recurrence. In the long duration group, univariate analysis revealed that old age, NYHA functional class, long AF duration, diabetes, and enlarged left atrium were associated with late AF recurrence. Multivariable analysis identified long AF duration as the only independent predictor of AF recurrence (Table 4).

\section{Echocardiographic outcomes}

Transthoracic echocardiographic follow up findings (median postoperative 91 months) in patients with sinus rhythm maintenance revealed that left atrial mechanical activity was less frequent in the control group than in the long duration group (Fig. 3a). Moreover, the mean left atrial volume index was lower in the long duration group compared with the control group (Fig. 3b).

\section{Discussion \\ Main findings}

We investigated the impact of cryoablation time during the maze procedure on clinical and long-term rhythm outcomes. Our main findings are that: 1) Ablation time did not have a significant effect on early postoperative outcomes; 2) the long duration group showed a higher rate of freedom from AF recurrence at 2 years than the control group; 3 ) the only predictor of AF recurrence was AF duration in both the control group and the long duration groups; and 4) the long duration group had superior outcomes to those of the control group in terms of atrial mechanical activity and left atrial reverse remodeling.
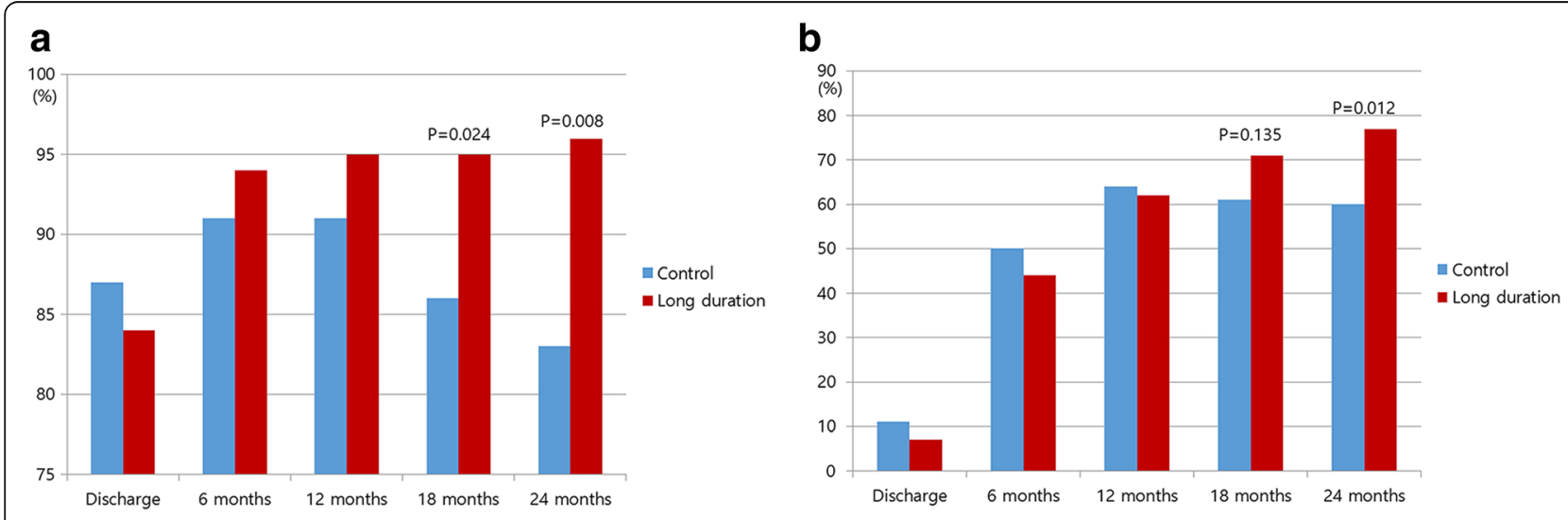

Fig. 2 Freedom from atrial fibrillation. All population (a) and Off drug population (b) 
Table 4 Predictors of AF recurrence at late follow up according to ablation duration

\begin{tabular}{|c|c|c|c|}
\hline \multirow[t]{2}{*}{ Variables } & \multirow{2}{*}{$\begin{array}{l}\text { Univariate } \\
P \text { value }\end{array}$} & \multicolumn{2}{|c|}{ Multivariate } \\
\hline & & $P$ value & OR $(95 \% \mathrm{Cl})$ \\
\hline \multicolumn{4}{|l|}{ Control group } \\
\hline Age, y & 0.041 & 0.125 & \\
\hline Female sex & 0.463 & & \\
\hline AF duration, months & 0.008 & 0.016 & $1.013(1.002-1.023)$ \\
\hline NYHA class & 0.094 & 0.130 & \\
\hline Diabetes & 0.127 & 0.394 & \\
\hline Hypertension & 0.250 & & \\
\hline $\mathrm{LAD}, \mathrm{mm}$ & 0.114 & 0.246 & \\
\hline \multicolumn{4}{|l|}{ Long duration group } \\
\hline Age, y & 0.594 & & \\
\hline Female sex & 0.424 & & \\
\hline AF duration, months & 0.064 & 0.049 & $1.007(1.001-1.013)$ \\
\hline NYHA class & 0.397 & & \\
\hline Diabetes & 0.205 & 0.084 & \\
\hline Hypertension & 0.044 & 0.008 & $1.062(1.016-1.110)$ \\
\hline $\mathrm{LAD}, \mathrm{mm}$ & 0.310 & & \\
\hline
\end{tabular}

$A F$ atrial fibrillation, NYHA New York Heart Association, $L A D$ left atrial diameter, $O R$ odds ratio, $\mathrm{Cl}$ confidence interval

\section{Impact of cryoablation time on rhythm outcomes}

$\mathrm{AF}$ is the most common type of chronic arrhythmia in the world, with an estimated prevalence of $0.4 \%-1 \%$ in the general population. AF is associated with an increased long-term risk of stroke, congestive heart failure, and mortality. The maze procedure is a useful modality for sinus rhythm restoration in patients with AF undergoing cardiac valve surgery. The contemporary modified Cox maze III procedure has an excellent success rate for sinus rhythm recovery, up to $90 \%[8,9]$. Among various energy sources such as radiofrequency, cryoablation, microwave, ultrasound, and laser energy, cryoablation is known to have the benefit of minimal damage to the endocardium and to create homogeneous transmural lesions [5]. The freezing and thawing form intracellular ice crystals, which are lethal to cardiomyocytes and result in irreversible lesions within $2 \mathrm{~h}$ after application [10]. By 12 weeks after application, sharply circumscribed, homogeneous, fibrotic full-thickness lesions develop [11, 12]. During nitrous oxide cryoablation, which is the technique used in the present study, the probe is cooled to $-60{ }^{\circ} \mathrm{C}$ for 1 to $2 \mathrm{~min}$. However, the ablation time needed to reach complete transmural freezing and "ice-ball" formation varies according to several factors such as left atrial wall thickness, degree of left atrial wall fibrosis, and area of the left atrium. Since there is no established protocol for ablation time in cryoablation, the ablation time is at the surgeon's discretion. Fukada and colleagues [13] applied cryoablation for $1 \mathrm{~min}$ at $-60{ }^{\circ} \mathrm{C}$. Manasse and colleagues [14] used applications of $2 \mathrm{~min}$ ( $3 \mathrm{~min}$ between the inferior left pulmonary vein and the posterior mitral leaflet) at $-60^{\circ} \mathrm{C}$. Most reported cryoablation procedures have used applications ranging from $90 \mathrm{~s}$ to $2 \mathrm{~min}$ at $-60{ }^{\circ} \mathrm{C}$ or $-80{ }^{\circ} \mathrm{C}$ [15-17]. In the present study, the long duration group had better outcomes than the control group with respect to sinus rhythm maintenance, both on and off drugs. We recommend that the cryoablation time should exceed $160 \mathrm{~s}$ to achieve optimal long-term rhythm outcomes. Further study with longer follow up is mandatory to shed light on the efficacy of long ablation duration for sinus rhythm maintenance.

\section{Left atrial reverse remodeling and ablation time}

The recovery of LA activity after the maze procedure can augment LV filling and stroke volume. Therefore, a lack of LA activity could predispose patients to the development of heart failure by decreasing forward cardiac output and elevating LA pressure. Furthermore, the recovery of LA activity may also contribute to the prevention of stroke or thromboembolism by increasing the blood flow velocity in the LA [18]. Even if sinus rhythm recovers after the maze operation, atrial mechanical function could remain impaired [19]. In a recent study

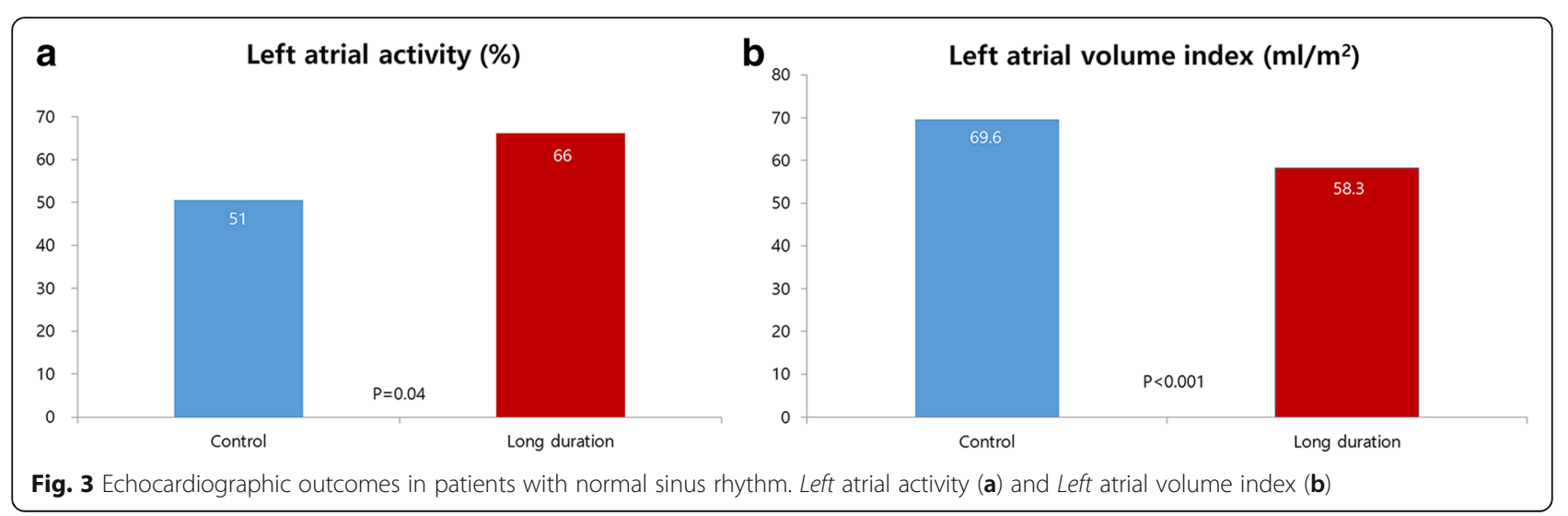


by Buber et al., 47 (31\%) of 150 patients who recovered SR after the maze operation showed no evidence of LA mechanical contraction on 3 month follow-up echocardiography [20]. Moreover, the absence of LA contraction resulted in a significant increase in the risk of thromboembolic stroke in patients with sinus rhythm [15]. We hypothesized that the control group would show better left atrial reverse remodeling, including recovery of left atrial activity and reduction of left atrial volume index, once the sinus rhythm was restored because more tissue damage is incurred with longer cryoablation durations. However, interestingly, the rate of left atrial activity recovery was higher in the long duration group than in the control group. Moreover, the left atrial volume index was also lower in the long duration group. One possible explanation is that the control group might have included more silent AF episodes that could be detected in spot eletrocardiography than the long duration group. Further studies using $48 \mathrm{~h}$ Holter monitoring or implantable eletrocardiography monitoring are necessary to test this hypothesis.

\section{Other clinical implications}

Nitrous oxide-based cryoprobes are reusable and costeffective. During the cryomaze procedure, we used two linear cryoprobes, either simultaneously or alternately. One probe was a $15^{\circ}$ angled $6 \mathrm{~cm}$ custom-made probe. The other was a T-shaped $4 \mathrm{~cm}$ linear probe that was custom designed for application at the LA posterior wall and right isthmus. We hypothesize that use of a long cryoprobe might reduce the overall application time. Furthermore, the use of a T-shaped linear probe might facilitate application onto the LA posterior wall, mitral annulus, and right isthmus.

Our modification of the cryomaze procedure is simple and provides excellent results. In particular, we demonstrated a reduced requirement for pacemaker implantation. A pacemaker was implanted in one patient $(0.4 \%)$ with the diagnosis of sick sinus syndrome, who has since maintained a regular rhythm without a pacing rhythm. The cryolesions resulting from our procedure are separate from the sinus node; this might reduce the risk of sick sinus syndrome due to sinus node devascularization and denervation.

\section{Study limitations}

Our study did have several limitations. First, this study was not a prospective randomized study; therefore, this study was inherently limited by its retrospective nature. However, our cohort is one of the largest to date, with most of the patients treated with the same procedure (cryomaze). In addition, the effect of left atrial activity on sinus/atrioventricular node function or the extent of atrial/perinodal fibrosis was not determined. Therefore, future prospective studies are needed to definitively establish the clinical implications of left atrial activity. The low incidence of permanent pacemaker implantation is another limitation of our study, which might be related to the very strict reimbursement policy in Korea. Our patient group has been followed with a uniform treatment plan $(>95 \%)$ by a single cardiac surgeon in our institute.

\section{Conclusion}

In conclusion, our modified cryomaze procedure using a long cryoprobe is safe and effective for the treatment of chronic AF. Cryoablation time plays an important role in achieving and maintaining the absence of AF. For this reason, we recommend longer cryoablation durations to achieve optimal cryomaze rhythm outcomes.

\section{Abbreviation}

AF: Atrial fibrillation; LA: Left atrium; LAVI: Left atrial volume index; LV: Left ventricle; NYHA: New York heart association

\section{Acknowledgements}

The authors thank Joong Hyun Ahn and Seon Woo Kim, PhD in the Division of Biostatistics at Samsung Medical Center for statistical support, and the database manager (Joomin Hwang).

Availability of data and supporting materials

Please contact author for data requests.

Funding

Not applicable.

Authors' contributions

DSJ carried out the study design, interpretation of data and participated in drafting the manuscript. JHY participated in the study design and data mining with interpretation. C-SJ participated in drafting the manuscript and revision. PWP carried out data analysis, interpretation, supervision and revision. KS participated in data mining and interpretation. WSk participated in data mining and drafting the manuscript. YTL carried out data interpretation and supervision. All authors read and approved the final manuscript.

Ethics approval and consent to participate

The Institutional Review Board of Sungkyunkwan University School of Medicine approved this study, and the requirement for patient consent was waived.

Consent for publication

Not applicable.

Competing interests

The authors declare that they have no competing interests.

\section{Publisher's Note}

Springer Nature remains neutral with regard to jurisdictional claims in published maps and institutional affiliations.

Received: 31 January 2017 Accepted: 12 July 2017

Published online: 24 July 2017

References

1. Prasad SM, Maniar HS, Camillo CJ, Schuessler RB, Boineau JP, Sundt TM 3rd, et al. The Cox maze III procedure for atrial fibrillation: long-term efficacy in patients undergoing lone versus concomitant procedures. J Thorac Cardiovasc Surg. 2003;126:1822-8.

2. Raanani E, Albage A, David TE, Yau TM, Armstrong S. The efficacy of the Cox/maze procedure combined with mitral valve surgery: a matched control study. Eur J Cardiothorac Surg. 2001;19:438-42. 
3. Lonnerholm S, Blomstrom P, Nilsson L, Oxelbark S, Jideus L, BlomstromLundqvist C. Effects of the maze operation on health-related quality of life in patients with atrial fibrillation. Circulation. 2000;101:2607-11.

4. Cox JL. Intraoperative options for treating atrial fibrillation associated with mitral valve disease. J Thorac Cardiovasc Surg. 2001;122:212-5.

5. Rodriguez LM, Leunissen J, Hoekstra A, Korteling BJ, Smeets JL, Timmermans C, et al. Transvenous cold mapping and cryoablation of the AV node in dogs: observations of chronic lesions and comparison to those obtained using radiofrequency ablation. J Cardiovasc Electrophysiol. 1998;9:1055-61.

6. Kim H, Park PW, Sung K, Lee YT, Jun TG, Kim WS, et al. Mid-term results of the Cox maze III procedure combined with open mitral commissurotomy for the treatment of rheumatic mitral stenosis. Circ J. 2010;74:1332-8.

7. Lang RM, Bierig M, Devereux RB, Flachskampf FA, Foster E, Pellikka PA, et al. Recommendations for chamber quantification: a report from the American Society of Echocardiography's guidelines and standards committee and the chamber quantification writing group, developed in conjunction with the European Association of Echocardiography, a branch of the European Society of Cardiology. J Am Soc Echocardiogr. 2005;18:1440-63.

8. Cox JL, Boineau JP, Schuessler RB, Kater KM, Lappas DG. Five-year experience with the maze procedure for atrial fibrillation. Ann Thorac Surg. 1993;56:814-23. discussion 823-4

9. Kim KC, Cho KR, Kim YJ, Sohn DW, Kim KB. Long-term results of the Cox-maze III procedure for persistent atrial fibrillation associated with rheumatic mitral valve disease: 10-year experience. Eur J Cardiothorac Surg. 2007;31:261-6.

10. Gage AA, Baust J. Mechanisms of tissue injury in cryosurgery. Cryobiology. 1998:37:171-86.

11. Gage AA, Baust JG. Cryosurgery - a review of recent advances and current issues. Cryo Letters. 2002;23:69-78.

12. Lustgarten DL, Keane D, Ruskin J. Cryothermal ablation: mechanism of tissue injury and current experience in the treatment of tachyarrhythmias. Prog Cardiovasc Dis. 1999:41:481-98.

13. Fukada J, Morishita K, Komatsu K, Sato H, Shiiku C, Muraki S, et al. Is atrial fibrillation resulting from rheumatic mitral valve disease a proper indication for the maze procedure? Ann Thorac Surg. 1998;65:1566-9. discussion 1569-70

14. Manasse E, Gaita F, Ghiselli S, Barbone A, Garberoglio L, Citterio E, et al. Cryoablation of the left posterior atrial wall: 95 patients and 3 years of mean follow-up. Eur J Cardiothorac Surg. 2003;24:731-40

15. Lee JW, Choo SJ, Kim Kl, Song JK, Kang DH, Song JM, et al. Atrial fibrillation surgery simplified with cryoablation to improve left atrial function. Ann Thorac Surg. 2001;72:1479-83.

16. Marui A, Nishina T, Tambara K, Saji Y, Shimamoto T, Nishioka M, et al. A novel atrial volume reduction technique to enhance the Cox maze procedure: initial results. J Thorac Cardiovasc Surg. 2006;132:1047-53.

17. Kondo $\mathrm{N}$, Takahashi $\mathrm{K}$, Minakawa M, Daitoku K. Left atrial maze procedure: a useful addition to other corrective operations. Ann Thorac Surg. 2003;75:1490-4.

18. Marui A, Saji Y, Nishina T, Tadamura E, Kanao S, Shimamoto T, et al. Impact of left atrial volume reduction concomitant with atrial fibrillation surgery on left atrial geometry and mechanical function. J Thorac Cardiovasc Surg. 2008;135:1297-305.

19. Park SJ, On YK, Kim JS, Jeong DS, Kim WS, Sung K, et al. Effect of left atrial activity after the maze procedure on clinical and echocardiographic outcomes. Circ J. 2014;78:1584-92

20. Buber J, Luria D, Sternik L, Raanani E, Feinberg MS, Goldenberg I, et al. Left atrial contractile function following a successful modified maze procedure at surgery and the risk for subsequent thromboembolic stroke. J Am Coll Cardiol. 2011;58:1614-21

\section{Submit your next manuscript to BioMed Central and we will help you at every step:}

- We accept pre-submission inquiries

- Our selector tool helps you to find the most relevant journal

- We provide round the clock customer support

- Convenient online submission

- Thorough peer review

- Inclusion in PubMed and all major indexing services

- Maximum visibility for your research

Submit your manuscript at www.biomedcentral.com/submit
Biomed Central 